\title{
Effects of postganglionic nerve stimulation in oesophageal achalasia: an in vitro study
}

\author{
A Tøttrup, A Forman, P Funch-Jensen, U Raundahl, K-E Andersson
}

\begin{abstract}
The functional postganglionic innervation of isolated smooth muscle strips from the oesophagogastric junction was examined in specimens taken from six achalasia patients and seven controls. Muscle strips representing either the longitudinal or the circular layer were prepared and mounted in organ baths and isometric tension was recorded. Electrical field stimulation, selectively exciting nerves, was applied. Strips from the circular layer from controls relaxed during field stimulation, an effect that was the result of stimulation of noncholinergic, non-adrenergic, inhibitory nerves. Circular muscle strips from achalasia patients contracted during field stimulation, an effect that was caused by muscarinic receptor activation. In one patient, atropine reversed the contraction to a relaxation. Longitudinal muscle strips contracted in response to stimulation in both controls and achalasia patients. This response was abolished by atropine. In conclusion the function of postganglionic inhibitory nerve fibres to the circular layer of the oesophagogastric junction is severely impaired in achalasia, while there is a conspicuous, functional cholinergic innervation.
\end{abstract}

Primary oesophageal achalasia is a motor disorder involving the smooth muscle portion of the oesophagus. The condition is characterised by incomplete relaxation of the lower oesophageal sphincter and absence of peristalsis in the oesophageal body in response to swallowing. ${ }^{12}$ Furthermore, a hypersensitivity to cholinergic drugs is seen, which is currently believed to be the result of denervation. ${ }^{34}$

Histologically, the most striking feature is loss of ganglion cells in the myenteric plexus, ${ }^{56}$ but also changes in the dorsal motor nucleus of vagus and in the vagus nerve have been reported in a limited number of autopsy studies. ${ }^{7}$ Thus, the primary site of the lesion is still debated, and previous pharmacological studies have not given detailed information about the function of the postganglionic innervation in this disorder.

The aim of the present study was to examine the function of the postganglionic innervation of the oesophagogastric junction in patients with achalasia using isolated muscle strips from both the longitudinal and circular layer in an organ bath model.

\section{Methods}

PATIENTS

Specimens were obtained from six patients (two women, four men) with achalasia, operated on with a modified cardiomyotomy. ${ }^{8}$ Median age was 32 years (range 14-68) and median duration of symptoms two years (range $3 / 4-14$ ). Throughout the length of the myotomy, a strip of the external muscular coat was excised. In five patients operated on for adenocarcinoma of the stomach, and two patients operated on for squamous cell carcinoma of the oesophagus, specimens from the oesophagogastric junction, taken $5-15 \mathrm{~mm}$ above the angle of His, served as controls. The control group included five women and two men with a median age of 69 years (range 38-77). The tissues were immediately placed in $4^{\circ} \mathrm{C}$ Krebs solution (for composition, see below) and carried to the laboratory. Isolated strips from either the longitudinal or the circular layer were prepared by microtechnique. Microscopic examination of the strips verified that dissection had been performed along the smooth muscle fibre direction. Only tissue macroscopically free from neoplastic lesions were used. The strips measured 1.5 to $4 \mathrm{~mm}$ in length and 0.5 to $1 \mathrm{~mm}$ in diameter. At each end, a silk thread was tied, and the strips were transferred to thermostatically controlled $5 \mathrm{ml}$ organ baths containing Krebs solution $\left(37 \cdot 0(0.5)^{\circ} \mathrm{C}\right)$ constantly bubbled with $5 \% \mathrm{CO}_{2}$ in $\mathrm{O}_{2}$. The final $\mathrm{pH}$ was $7 \cdot 40(0 \cdot 05)$. After a calibration period of at least one hour, the preparations were mounted between two small, L-shaped hooks. One hook was attached to a force transducer (Grass FT03) and the other was connected to a sledge which allowed adjustments of length of the strip. Isometric tension was registered on a six channel Grass Polygraph.

The distance between the two hooks was increased rapidly to a small preload of $0.1 \mathrm{mN}$. Tension then immediately fell to the level defined by the output from the unloaded transducer. The length between the two knots of the silk threads was measured by a stereomicroscope equipped with an ocular micrometer, and this length was defined as the resting length, $L_{R}$. Adjustment was now performed to secure a distance between the two knots of $200 \%$ of $L_{R}$. At this elongation, near optimum mechanical responses are achieved in isolated smooth muscle from the human oesophagogastric junction." After a calibration period of at least two hours, transmural field stimulation was applied to the preparations. This was delivered by a Grass S48 stimulator through two isolation units (SIU5). Two platinum wire electrodes placed parallel at each side of the strips with a distance of $1 \mathrm{~mm}$ to the preparation were connected to the output of the isolation units. Square waves of $0.4 \mathrm{msec}$ duration were delivered in trains of five seconds at supramaximal voltage. The interval between the trains was two minutes. Strips from the circular layer were stimulated with a frequency of $10 \mathrm{~Hz}$, and strips from 
the longitudinal layer were stimulated with a frequency of $40 \mathrm{~Hz}$. These frequency values are optimal for the inhibitory responses normally seen in circular muscle strips and for contractions in longitudinal muscle strips, respectively. ${ }^{10}$

The protocol was approved by the local ethical committee.

\section{COMPOSITION OF SOLUTIONS}

Krebs (mM): $\mathrm{NaCl} 119, \mathrm{KCl} 4 \cdot 6, \mathrm{NaHCO}_{3} 15$, $\mathrm{CaCl}_{2} 1 \cdot 5, \mathrm{MgCl}_{2} 1 \cdot 2, \mathrm{NaH}_{2} \mathrm{PO}_{4} 1 \cdot 2$, glucose 11 . $\mathrm{Ca}^{++}$-free medium $(\mathrm{mM}): \mathrm{NaCl} 119, \mathrm{KCl} 4 \cdot 6$, $\mathrm{NaHCO}_{3} 15, \mathrm{MgCl}_{2} 1 \cdot 2, \mathrm{NaH}_{2} \mathrm{PO}_{4} 1 \cdot 2$, glucose 11 , Ethyleneglycol-bis- $\beta$-amino- $\mathrm{N}-\mathrm{N}$ tetracetate (EGTA) 0.01.

\section{DRUGS}

Carbamoylcholine chloride (carbachol, Sigma), papaverine sulphate (Danish Pharmacy Laboratories, DAK), tetrodotoxin (TTX, Sigma), atropine sulphate (DAK), phentolamine methane sulphonate (Ciba), propranolol chloride (Ferrosan), ketanserin (Janssen).

\section{Results}

In both control and achalasia patients, circular strips from the oesophagogastric junction invariably developed active resting tension, which was completely abolished by replacing the Krebs solution with $\mathrm{Ca}^{++}$-free medium. Thus, no further relaxation was achieved with addition of papaverine $\left(10^{-4} \mathrm{M}\right)$, and the remaining baseline tension therefore reflected the contribution from passive elastic tissue components. Readdition of $\mathrm{Ca}^{++}$by replacing with Krebs solution restored tension within five minutes.

In longitudinal muscle strips, the tension applied by stretching the preparation was unaffected by treatment in $\mathrm{Ca}^{++}$-free medium, or by exposure to papaverine $\left(10^{-4} \mathrm{M}\right)$.

\section{CIRCULAR MUSCLE LAYER}

\section{Controls}

In strips from the circular muscle layer $(n=18)$ from control patients, field stimulation caused immediate relaxation to the baseline tension, sometimes followed by a contraction after cessation of the stimulus (Fig la). This relaxation was unaffected by atropine $\left(10^{-6} \mathrm{M}\right)$, phentolamine $\left(10^{-6} \mathrm{M}\right)$, propranolol $\left(10^{-6} \mathrm{M}\right)$, and ketanserin $\left(10^{-6} \mathrm{M}\right)$, but completely abolished by tetrodotoxin (TTX) $\left(3 \times 10^{-7} \mathrm{M}\right)$. The after-contraction was reduced by $40 \%(28-53 \%)$ by addition of atropine, and completely abolished by tetrodotoxin.

\section{Achalasia}

In circular muscle strips $(n=19)$ from patients with achalasia, no relaxation during field stimulation was recorded. Instead, a contraction beginning shortly after initiation of the stimulus was elicited, declining after cessation of the stimulus. The contraction was completely

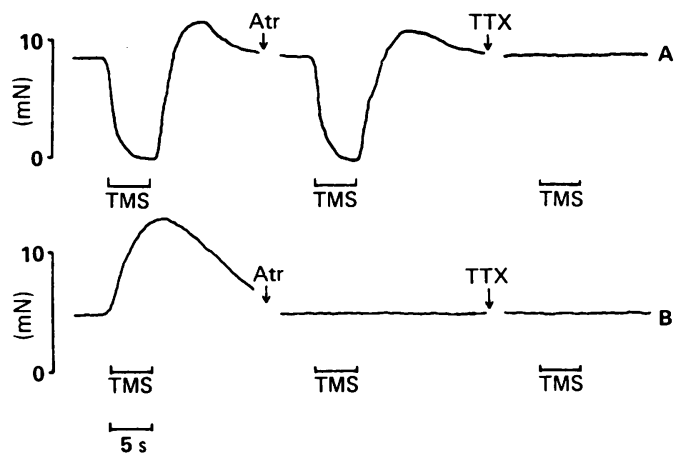

Figure 1: (a) Tracing from a control patient showing the effect of transmural field stimulation $(T M S)$ (supramaximal voltage, $10 \mathrm{~Hz}$, impulse duration $=0.4 \mathrm{~ms}$, train duration = $5 \mathrm{~s})$ on a circular muscle strip from the oesophagogastric junction. Atropine (Atr) does not affect relaxation, but the 'off'-contraction in inhibited. Tetrodotoxin (TTX) completely abolishes both responses. (b) Typical tracing from the circular muscle layer of the oesophagogastric junction in a patient with achalasia showing a contraction during field stimulation (TMS). The contraction is abolished by Atr and TTX. In both tracings the zero line is defined as the tension reached after exposing the strips to $\mathrm{Ca}$ '

inhibited by both atropine $\left(10^{-6} \mathrm{M}\right)$ and tetrodotoxin $\left(3 \times 10^{-7} \mathrm{M}\right)$ (Fig lb).

In strips from one patient, atropine lowered tension and reversed contraction to a minor relaxation approximately $30-35 \%$ of the active resting tension (Fig 2).

\section{LONGITUDINAL MUSCLE LAYER}

\section{Controls and achalasia}

Strips from the longitudinal muscle layer always contracted during field stimulation, and this contraction was completely abolished by atropine in both achalasia $(n=11)$ and control strips $(n=14)$ (Fig 3$)$. In achalasia strips, the contractile response tended to continue to increase after cessation of the stimulation in contrast with the rapid decline in controls. Thus, the contractile response was more prolonged in longitudinal muscle strips from achalasia patients than in preparations from controls.

\section{Discussion}

A crucial finding in oesophageal achalasia is lacking or incomplete relaxation of the lower oesophageal sphincter in response to deglutition.

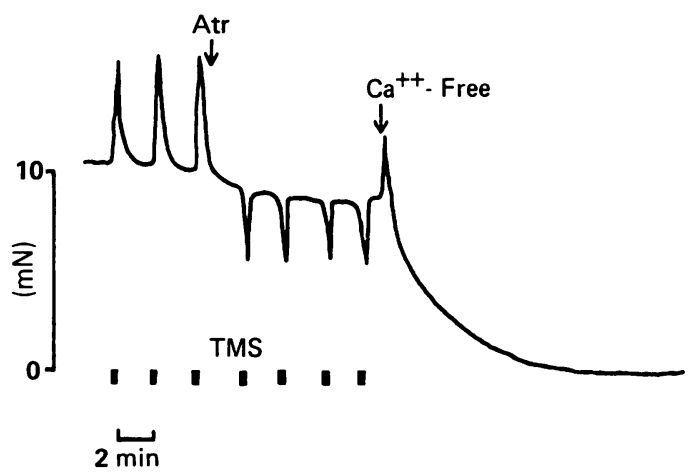

Figure 2: Circular muscle strip from the oesophagogastric junction in a patient with achalasia showing contractions during transmural field stimulation (TMS). Atropine (Atr) lowers basal tension slightly, and reverses contraction to a weak relaxation. $C a^{\prime}$ '-free medium abolishes resting tension. 


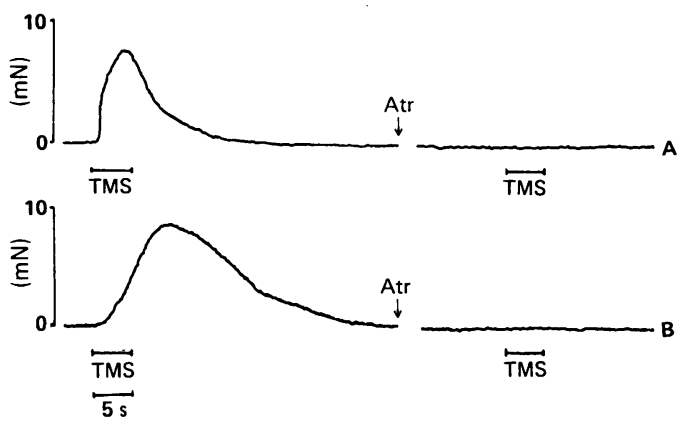

Figure 3: Tracings from the longitudinal muscle layer of the oesophagogastric junction showing the effects of transmural field stimulation (TMS). (a) Control strip. During TMS a contraction is evoked, and the strip relaxes rapidly after

cessation of the stimulus. Atropine (Atr) abolishes the response. (b) Achalasia strip. The contractile response elicited by TMS reaches maximum a few seconds after cessation of the stimulus, and relaxes slowly to base line. The response is abolished by atropine.

The reason for this functional failure of the sphincter is not well understood. The current view is that the condition is caused by a disturbance in the nervous control of the organ. ${ }^{11}$ This nervous disturbance could be located at any site from the vagal centres in the medulla oblongata to the neuromuscular junction in the oesophageal wall. "In fact, pathological changes have been reported in the oesophageal wall, ${ }^{5-7}$ the vagus nerve, ${ }^{12}$ and the dorsal motor nucleus of the vagus.?

Previous in vitro studies of muscle strips from the oesophagogastric junction in patients with achalasia are few, ${ }^{613-15}$ and only two of these include strips from the circular muscle layer. ${ }^{613}$ Nicotine, a ganglionic stimulant, which normally relaxes circular muscle strips from the oesophagogastric junction, gave no response in one strip from a patient with achalasia. ${ }^{6}$ In another study including circular muscle strips from two patients, field stimulation elicited a contraction mediated by muscarinic receptors. ${ }^{13}$

In this study a relaxation could always be elicited in circular muscle strips from the oesophagogastric junction of controls. This relaxation, which was due to stimulation of postganglionic, inhibitory fibres, may be equivalent to the relaxation of the lower oesophageal sphincter elicited in vivo by swallowing. In similar strips from achalasia patients, this inhibitory response was never seen. Instead, all strips contracted as a result of activation of muscarinic receptors. In five patients, blockade of muscarinic transmission with atropine abolished contractions, and left the strips unresponsive to field stimulation. In one patient atropine reversed the contraction to a small relaxation. Thus, the normal, very pronounced, non-cholinergic, non-adrenergic inhibitory response was absent in five of six patients with achalasia, and only a remnant was demasked by muscarinic blockade in the remaining patient.

Despite the absence of relaxation in response to transmural field stimulation, achalasia strips could be relaxed to base line by removal of extracellular calcium, a finding that may have clinical implications.

Longitudinal strips from achalasia and controls contracted because of muscarinic receptor activation. The response in achalasia strips, however, was more prolonged than in controls. This could indicate differences in neuromuscular transmission or in contractile activation.

Cholinergic fibres are present in the normal lower oesophageal sphincter, and contribute to a considerable part of resting tone. ${ }^{1617}$ In this study, atropine did not lower tension in isolated strips from the oesophagogastric junction, but the presence of cholinergic innervation in the normal oesophagogastric junction was illustrated by the finding that atropine inhibited the 'off' contraction of the circular muscle layer by $40 \%$. In longitudinal and circular muscle strips from achalasia patients pronounced contractions were shown mediated by muscarinic receptors, and thus possibly caused by stimulation of cholinergic nerves. Several other lines of evidence point at a functional cholinergic innervation of the lower oesophageal sphincter in achalasia. Based on the effects of atropine, the integrity of cholinergic nerves was considered either normal or only minimally impaired in a manometric study of the lower oesophageal sphincter in achalasia patients. ${ }^{18}$ Moreover, the responsiveness of the lower oesophageal sphincter to increase in abdominal pressure, an effect that is vagally mediated, was normal in eight of 10 patients with untreated achalasia. ${ }^{19}$ Finally edrophonium, a cholinesterase inhibitor, was reported to increase sphincter tone in these patients, indicating an intact, postganglionic cholinergic supply to the sphincter. ${ }^{20} \mathrm{~A}$ hypersensitivity to cholinergic agents has been reported in achalasia, however, ${ }^{34}$ a feature that was attributed postganglionic denervation according to the law of Cannon. We did not examine the sensitivity to acetylcholine or other drugs acting on muscarinic receptors, but preliminary experiments do not indicate a supersensitivity to carbachol in isolated muscle strips from patients with achalasia.

Paradoxical sphincter contraction after cholecystokinin has been reported ${ }^{21}$ a characteristic that was attributed impairment or absence of postganglionic inhibitory fibres.

The contractile response to transmural field stimulation in achalasia replacing the normal relaxant response may also be correlated to morphological findings in achalasia patients. The most conspicuous finding in histological examinations of the oesophagogastric junction in achalasia is severe loss of ganglia in the myenteric plexus. ${ }^{5-7}$ The application of refined histological techniques has given detailed information about various transmitters and transmitter candidates in achalasia. Thus, vasoactive intestinal polypeptide, a candidate for lower oesophageal sphincter relaxation, was lacking in specimens from the oesophagogastric junction in achalasia. ${ }^{22}$ In a report from the same group, substance $P$ and enkephalin were not affected to the same extent, ${ }^{23}$ which could indicate a certain selectivity of the neuronal impairment. Earlier studies have shown acetylcholinesterase activity in tissue from the oesophagogastric junction but not from the oesophageal body, ${ }^{2+}$ suggesting a cholinergic innervation of the oesophagogastric junction.

The significance of these findings should be interpreted in the light of our current knowledge about the control of oesophageal peristalsis. 
Primary peristalsis in initiated by vagal discharge, but propagation of contractions in the smooth muscle portion of the oesophagus as well as lower oesophageal sphincter relaxation is probably controlled by peripheral, intramural mechanisms." These mechanisms, which in the human sphincter include: (1) non-adrenergic relaxation, (2) non-cholinergic, non-adrenergic contraction, and (3) cholinergic contraction, were differently affected in achalasia strips. The first two were definitely impaired, whereas a contraction mediated through muscarinic receptors was prominent.

The cause of achalasia is unknown. In Chagas' disease, local invasion of Trypanozoma cruzi in the oesophageal wall is followed by neuronal damage and secondary achalasia, which is only distinguished from primary achalasia by serological tests. ${ }^{26}$ If local factors are also responsible for the neuronal impairment in primary achalasia, a clear selectivity is needed. Alternatively, a compensatory mechanism with reinnervation by extrinsic vagal fibres could explain the presence of a strong, but inappropriate, cholinergic innervation.

In conclusion, this study shows a severe functional impairment of postganglionic inhibitory nerve function of the oesophagogastric junction in achalasia patients. A marked contraction mediated by muscarinic receptors was demonstrated, indicating either selectivity of the neuronal lesion or reinnervation by extrinsic, cholinergic fibres.

Finn Hanberg Sørensen, Jørgen Boné, Svend Arne Pedersen, Pål Wara, Ib Balslev, and Povl Bach-Nielsen are thanked for their skillful assistance with the removal of biopsies.

1 Cohen S, Lipshutz W. Lower esophageal dysfunction in achalasia. Gastroenterology 1971; 61:814-20.

2 Pope CE. Motor disorders of the esophagus. Postgrad Med 1977; 61: 118-25.

3 Cohen BR, Guelrud M. Cardiospasm in achalasia: demonstration of supersensitivity of the lower esophageal sphincter. Gastroenterology 1971; 60: 769.

4 Kramer P, Ingelfinger FJ. Esophageal sensitivity to mecholy in cardiospasm. Gastroenterology 1951; 19: 242-53.

5 Csendes A, Smok G, Braghetto I, Ramirez C, Velasco N,
Henriques A. Gastroesophageal sphincter pressure and histological changes in distal esophagus in patients with achalasia of the esophagus. Dig Dis $S_{c i}$ 1985; 30: 941-5.

6 Misiewicz JJ, Waller SL, Anthony PP, Gummer JWP. Achalasia of the cardia: Pharmacology and histopathology of isolated cardiac sphincteric muscle from patients with and without achalasia. Q7 Med 1969; 149: 17-30.

7 Cassela RR, Brown AL, Sayre GP, Ellis FH. Achalasia of the esophagus: pathologic and etiologic considerations. Ann Surg 1964; 160: 474-86.

8 Csendes A, Velasco N, Braghetto I, Henriques A. A prospective randomised trial comparing forceful dilatation pective randomised trial comparing forceful ditatation and esophagomytomy in patients with ach
esophagus. (jastroenterology 1981; 80: 789-95.

9 Tottrup A, Forman A, Uldbjerg N, Funch-Jensen P, Andersson K-E. Mechanical properties of isolated human osophageal smooth muscle. Am $\mathcal{F}$ Phvsiol (In press).

10 Tottrup A, Forman A, Funch-Jensen P, Raundahl U, Andersson K-E. Effects of transmural field stimulation in isolated muscle strips from human esophagus. Am $\mathcal{Y}$ Phvsiol (In press).

11 Feldman M. Esophageal achalasia syndromes. Am f Med Sci 1988; 295: 60-81

12 Cassela RR, Ellis RH, Brown AL. Fine structure changes in achalasia of the esophagus. I. Vagus nerves. Am .7 Pathol 1965; 46: 279-88.

13 Adams CW M, Brain RHF, Ellis FG, Kraunte R, Trounce JR. Achalasia of the cardia. (juy Hosp Rep 1961; 110: 191 JR. 236 .

$1+$ Trounce JR, Deuchar DC, Kauntze R, Thomas (iA. Studies in achalasia of the cardia. Q. F Med 195\%; 104: $433-43$.

15 Ellis FG, Kauntze R, Nightingale A, Trounce TR. Further studies in achalasia of the cardia. Qf Med 1959;29: 305-12.

16 Dodds WJ, Dent J, Hogan WJ, Arndorfer RC. Effect of atropine on esophageal motor function in humans. A $m . \mathcal{F}$ Physiol 1981; 240: 290-6.

17 Lind JF, Crispin JS, McIver DK. The effect of atropine on the gastroesophageal sphincter. Can F Physiol Pharmacol 1968: 46: $233-8$.

18 Holloway RH, Dodds WJ, Helm JF, Hogan WJ, Dent J, Arndorfer RC. Integrity of cholinergic innervation to the lower esophageal sphincter in achalasia. (jastroenterology 1986; 90: $92+9$.

19 Atkinson M, Ogilvie AL, Robertson CS, Smart HI. V'agal function in achalasia of the cardia. (IF Med 1987; 63: 297-
for 303 .

20 Cohen S, Fisher R, Tuch A. The site of denervation in achalasia. Gut 1972; 13: 556-8

21 Dodds WJ, Dent J, Hogan WJ, Patel GK, Toouli J, Arndorfer RC. Paradoxical lower esophageal sphincter contraction induced by cholecystokinin-octapeptide in patients with achalasia. Gastroenterology 1981; 80: 327-33.

22 Aggestrup S, Uddmann R, Sundler F, et al. Lack of vasoactive intestinal polypeptide nerves in esophageal achalasia. intestinal polypeptide nerves

23 Aggestrup S, Uddman R, Jensen SI, et al. Regulatory peptides in the lower esophageal sphincter of man. Regul Pept 1985; 10: 167-78.

24 Adams CWM, Marples EA, Trounce JR. Achalasia of the cardia and Hirschprung's disease. The amount and distribucardia and Hirschprung's disease. The amount and

25 Christensen J. Motor functions of the larynx and esophagus. In: Johnson LR, ed. Physiology of the gastrointestinal tract. Volume 1. 2nd ed. New York: Raven, 1987: 595-612.

26 Köberle F. Chagas' disease and Chagas' syndromes: The pathology of American trypanosomiasis. Adv Parasitol 1968 6: 63-116. 